\title{
Effect of Acidic salts on Characteristics of Precipitated Silica from Geothermal Sludge
}

\author{
Srie Muljani ${ }^{1}$, Ely Kurniati \\ Chemical Engineering Department \\ Universitas Pembangunan Nasional "Veteran" Jawa Timur \\ Surabaya, Indonesia \\ ${ }^{1}$ sriemuljani.tk@upnjatim.ac.id
}

\begin{abstract}
This research was carried out to produce precipitated silica from sodium silicate using acidic salt as precipitator. The aim of this research is to study the effects of acidic acid on precipitated silica characterization. The sodium silicate solution was produced by extraction of geothermal sludge using sodium hydroxide $2 \mathrm{~N}$ solution. Precipitated silica products were characterized by $\mathbf{x}$-ray diffraction, $x$-ray fluorescence and scanning electron microscopy. The results showed that the silica precipitated prepared by aluminum sulfate solution (1-3N) is a silica-alumina composite, amorphous structure and about 0.5 millimicron particle size. Precipitated silica with a concentration of $91-99 \% \mathrm{SiO}_{2}$ can be produced from sodium silicate solution using 1-3N sodium dihydrogenphospate solutions, have an amorphous structure and 1-2 millimicron particle size. Microscopically precipitated silica prepared by aluminum sulfate has a softer structure than that of precipitated silica prepared by sodium dihydrogen phosphate.
\end{abstract}

Keywords-Acidic salt, precipitated silica, geothermal sludge, silica alumina

\section{INTRODUCTION}

The production of precipitated silica starts with the reaction of an alkaline silicate solution with a mineral acid. It was also found that ionic strength, over cation identity, determines silica polymerization and particle flocculation rates [1]. From the reaction of silicate solution and mineral acid described previously, different silica products can be formed, namely silica gel or precipitated silica. Patterson [2] have been reported the uses and nomenclature of synthesis silica gels and precipitated silica that are significant commercial importance. The formation of silica gel may be more domination by polymerization from monomers silisic, while precipitated more domination by flocculation and sedimentation of particle silica. Precipitated silica has found various applications as filler in rubber and plastics, absorbent, carrier, drying powder, substrate, catalysts, anticorrosion agent, defoamer, etc. The properties of precipitated silica depend strongly on the conditions of its synthesis, such as the synthesis temperature, time of precipitation, $\mathrm{pH}$, addition of coagulant, and modes of washing and drying. These factors influence the size of the silica particles, their aggregation and specific surface area.

This research was carried out to produce the precipitated silica in addition to knowing the effects of acidic acids on characteristics of silica precipitates. Chen et al [5] reported the preparation of precipitated silica using sulfuric acid as precipitator from sodium silicate prepared by corn straw ash. Sodium silicate solution has also been prepared by geothermal extraction using $\mathrm{NaOH}$ solution [2]. The sodium silicate solution commonly is alkaline solution ( $\mathrm{pH} \mathrm{13-14).} \mathrm{Addition}$ of acidic salts with a certain concentration will reduce the $\mathrm{pH}$ of the solution. Silicon was exits in the form of $\mathrm{SiO}_{3}{ }^{+2}$ in alkaline solutions and in the form of monosilisic acid if the $\mathrm{pH}$ solution value in the range of 1-8 [6]. But if the $\mathrm{pH}$ silica solution is below $\mathrm{pH} \mathrm{7,} \mathrm{the} \mathrm{alkaline-silica} \mathrm{solution} \mathrm{may}$ produce the silica gel. Precipitated silica can be produced at a pH susceptibility above 7 . Therefores the concentration and acidic salts volume influence to keep the $\mathrm{pH}$ of the alkaline silica solution not below value of $\mathrm{pH} 7$ and produce silica gel.

This study used the acid salt to produce precipitated silica is sodium dihydrogen phosphate $\left(\mathrm{NaH}_{2} \mathrm{PO}_{4}\right)$ and Aluminum Sulfate $\left(\mathrm{Al}_{2}\left(\mathrm{SO}_{4}\right)_{3}\right)$. Aluminium salts can react with silica to produce silica-alumina compounds [6]. The morphology of precipitated silica was analyzed by scanning electron microscopy. Meanwhile, to find out the product composition was using $\mathrm{X}$-ray fluorescence and to determine the crystallinity of the product using X-ray diffraction.

\section{MATERIALS AND MeTHODS}

\section{A. Materials}

Silica source for this study is obtained from geothermal plant, PLTPB Dieng Wonosobo as solid waste, namely geothermal sludge. The XRF analysis on geothermal sludge particles showed that the concentration of silica is $97.3 \mathrm{w} \%$ and other components in the form of $\mathrm{K}_{2} \mathrm{O}, \mathrm{CaO}, \mathrm{MnO}, \mathrm{Fe}_{2} \mathrm{O}_{3}$. Acid salts, aluminum sulfate $\left(\mathrm{Al}_{2}\left(\mathrm{SO}_{4}\right)_{3}\right)$ and sodium dihydrogen phosphate $\left(\mathrm{NaHPO}_{4}\right)$ obtained from chemical distributor CV Medica Vanjaya.

\section{B. Preparation of sodium silicate from geothermal sludge}

Geothermal sludge is dried, to reduce water content, and a reduction in size is then sieved with a size of 100 mesh. Sodium silicate prepared by extracting $62 \mathrm{~g}$ of geothermal sludge powder with a solution of sodium hydroxide $(\mathrm{NaOH}) 2$ $\mathrm{N}$ at $100^{\circ} \mathrm{C}$ for 60 minutes using hot plate stirrer. The reactions that occur in the formation of sodium silica are as follows [2]:

$$
\mathrm{SiO}_{2(\mathrm{~s})}+2 \mathrm{NaOH}_{(\mathrm{aq})} \rightarrow \mathrm{Na}_{2} \mathrm{SiO}_{3(\mathrm{aq})}+\mathrm{H}_{2} \mathrm{O}_{(\mathrm{l})}
$$


$250 \mathrm{ml}$ sodium silicate solution was obtained from the extraction is then diluted by demineralized water in a ratio of $1: 1 ; 1: 2 ; 1: 3 ; 1: 4$ and 1: 5 respectively. From the dilution, the concentration of silica in sodium silicate was obtain in the range of about $2.9 ; 2.6 ; 2.1 ; 1.6 ; 1.2 \mathrm{w} \% \mathrm{SiO}_{2}$ respectively.

\section{Preparation of Precipitated Silica}

The sodium silicate is titrated with acid salts according to the concentration in the range of $1-3 \mathrm{~N}$ until the mixture reaches $\mathrm{pH} 7$. After reaching $\mathrm{pH} 7$ the mixture is allowed to stand until deposition occurs. Then silica separated from filtrate by filtration using wachtman paper. Precipitated silica is dried using an oven at a temperature of $100^{\circ} \mathrm{C}$ to remove water content in silica precipitate products.

\section{Characterization}

Silica precipitate products were analyzed using scaning electron microscopy (SEM) to determine the particle morphology, pore diameter, and particle size. X-ray fluoroscence analysis for determined the composition of the product and its purity. X-ray diffraction analysis was to find out the classification of crystal structures and product impurities.

\section{RESULT AND DISCUSSION}

Fig.1. showed diffraction patterns for silica precipitate products before washing prepared by $\mathrm{NaH} 2 \mathrm{PO} 4$ (Fig.1a) and prepared by Al2(SO4)3 (Fig.1b). A peak widens was appears from 15 to 25 angle which indicated the amorphous phase in both product. There appear to be many sharp peaks that indicated the presence of impurities salts in precipitated products, especially precipitated silica product prepared by $\mathrm{NaHPO}_{4}$

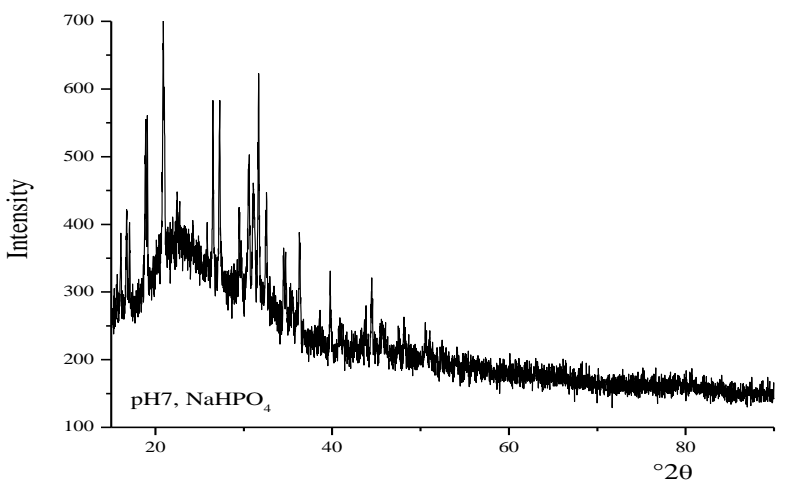

(a)

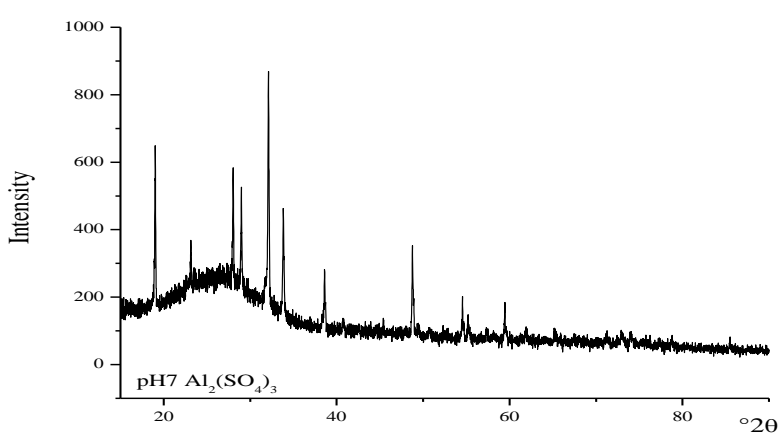

(b)

Fig. 1. X-ray diffraction pattern of precipitated silica before washing prepared by a) $\mathrm{NaHPO}_{4}$ and b) $\mathrm{Al}_{2}(\mathrm{SO} 4)_{3}$ solution

Fig.2 showed the diffraction pattern of precipitated silica after washing. The washing operation showed that it was able to remove the impurities salts from precipitated silica product. This is indicated by the loss of sharp peaks in precipitated silica product diffraction pattern.

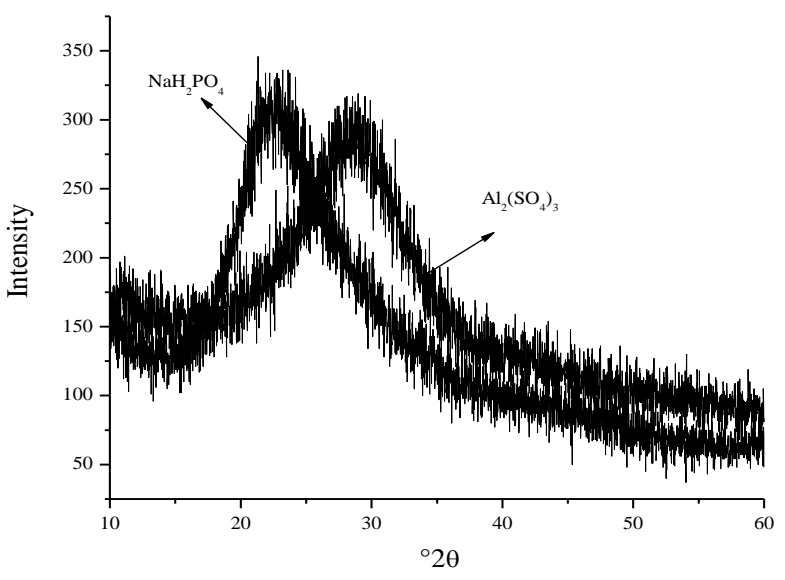

Fig. 2. X-ray diffraction pattern of precipitated silica after washing prepared by $\mathrm{NaHPO}_{4}$ and $\mathrm{Al}_{2}(\mathrm{SO} 4)_{3}$ solution

\section{A. Effect of Acid Salt Solution on composition of precipitated silica.}

Fig.3. showed the effect of $\mathrm{Al}_{2}\left(\mathrm{SO}_{4}\right)_{3}$ salt solution concentration on concentration of silica $\left(\mathrm{SiO}_{2}\right)$ in precipitated silica. Based on the results of XRF analysis (fig.3a), it can be seen that the greater the concentration of sodium silicate from 1.2 to $2.9 \%$, the lower the concentration of silica in the product. The greater the concentration of $\mathrm{Al}_{2}\left(\mathrm{SO}_{4}\right)_{3}$ solution from 1 to $2 \mathrm{~N}$ the silica concentration in product was decreases, but then there is an increase in the concentration of silica product along with the increase in the concentration of $\mathrm{Al}_{2}\left(\mathrm{SO}_{4}\right)_{3}$ solution from $2 \mathrm{~N}$ to $3 \mathrm{~N}$. The formation of precipitated silica at the concentration sodium silicate $2.9 \%$ and the concentration of $3 \mathrm{~N}$ saline solution produce a product with a silica concentration of $68.9 \%$. The opposite effect occurs in aluminum concentrations in silica products (Fig. 3b). 
The greater the concentration of sodium silicate solution from 1.2 to $2.9 \%$, the higher the concentration of $\mathrm{Al}_{2} \mathrm{O}$ in precipitated silica products. On the other hand, the concentration of $\mathrm{Al}_{2} \mathrm{O}$ increases with the increase of salt concentration from 1 to $2 \mathrm{~N}$, then the concentration of $\mathrm{Al}{ }_{2} \mathrm{O}$ decreases with the increase of $\mathrm{Al}_{2}\left(\mathrm{SO}_{4}\right)_{3}$ concentration from 2 to $3 \mathrm{~N}$.

The XRF analysis results also showed that in the precipitated silica product prepared by $\mathrm{Al}_{2}\left(\mathrm{SO}_{4}\right)_{3}$ solution it was proved that the $\mathrm{Al}_{2} \mathrm{O}$ element was not lost by the washing operation. There were no sharp peaks in the diffraction pattern as explained previously it can prove that $\mathrm{Al}_{2} \mathrm{O}$ binds to silica to form composites while $\mathrm{NaH}_{2} \mathrm{PO}_{4}$ salts are limited to matrix formation with silica making it easy to wash.

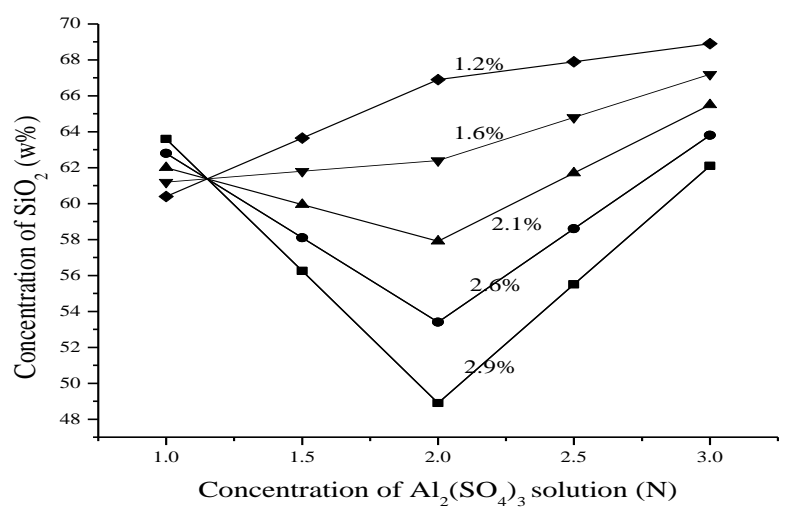

(a)

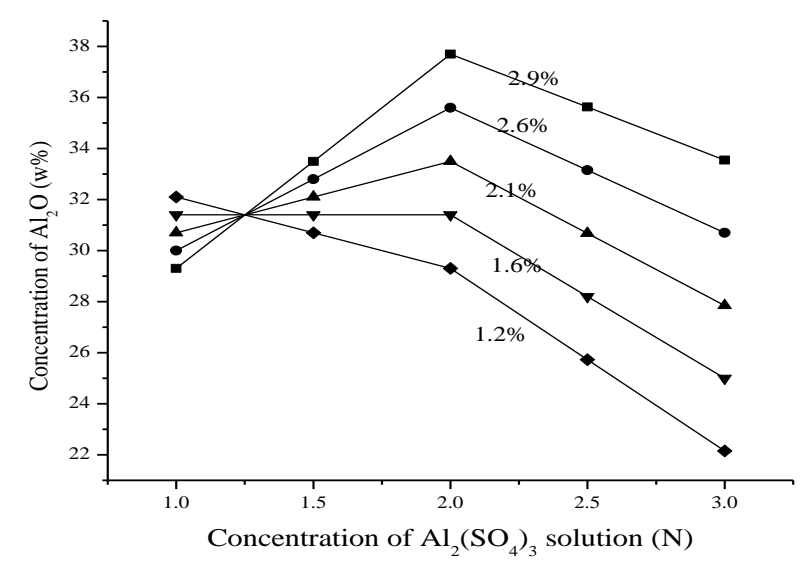

(b)

Fig. 3. The effect of $\mathrm{Al}_{2}\left(\mathrm{SO}_{4}\right)_{3}$ salt concentration on concentration of silica $\left(\mathrm{SiO}_{2}\right)$ in precipitated silica product.

Fig.4 showed the concentration of silica in the precipitated product prepared by NaHPO4. Silica concentration in products ranges from 91 to $99 \%$. Higher purity was obtained in silica products precipitated from NaHPO4 compared to silica products precipitated from $\mathrm{Al} 2$ (SO 4) 3. This may be due to the fact that aluminum binds chemically with silica so it is difficult to wash aluminum salts compared to washing phosphate salts.
The purity of precipitated silica prepared by $\mathrm{NaH}_{2} \mathrm{PO}_{4}$ also proves that all phosphate salts can be washed with demineralized water. The highest purity was achieved at low sodium silicate concentrations of $1.2-1.6 \%$. At low sodium silicate concentrations there is almost no effect of salt concentration $(1-3 N)$. The greater the acidic salt concentration shows the higher the concentration of silica in the product. A similar phenomenon with the use of $\mathrm{Al}_{2}\left(\mathrm{SO}_{4}\right)_{3}$ solution for sodium silicate concentration $2.1-2.9 \%$, namely a decrease in silica concentration along with a decrease in salt concentration from 1-2 $\mathrm{N}$ but not as sharp as the decrease in the use of $\mathrm{Al}_{2}\left(\mathrm{SO}_{4}\right)_{3}$. Furthermore, the concentration increases sharply with an increase in salt concentration from 2 to $3 \mathrm{~N}$. Almost all concentrations of sodium silicate from $1.2-2.9 \%$ of precipitated silica products can reach $99 \%$ purity when using $\mathrm{NaH}_{2} \mathrm{PO}_{4}$ salt with a concentration of $3 \mathrm{~N}$.

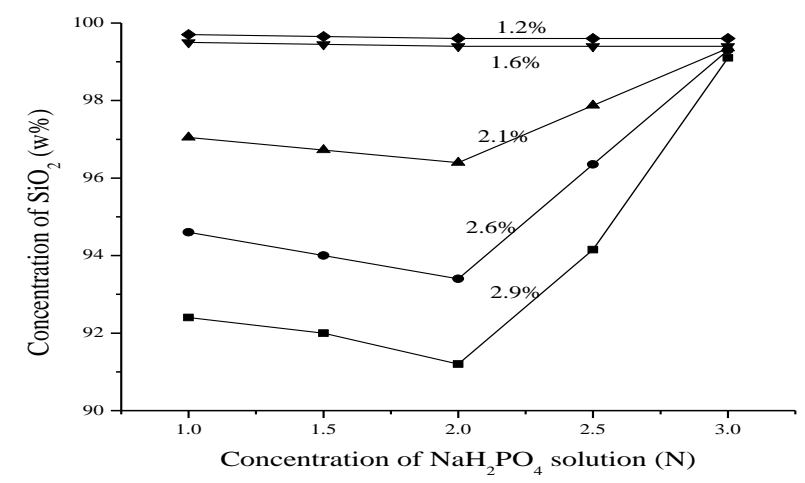

Fig. 4. The effect of $\mathrm{NaH}_{2} \mathrm{PO}_{4}$ concentration on concentration of silica $\left(\mathrm{SiO}_{2}\right)$ in precipitated silica product

\section{Morphology of precipitated silica products}

Fig.5. showed the microscopy of precipitated silica prepared by a) $\mathrm{Al}_{2}\left(\mathrm{SO}_{4}\right)_{3}$ and b) $\mathrm{NaH}_{2} \mathrm{PO}_{4}$ using sodium silicate solution concentration of $1.6 \%$ at magnification 10000x. Microscopically precipitated silica prepared by $\mathrm{Al}_{2}\left(\mathrm{SO}_{4}\right)_{3}$ has a softer structure than that of precipitated silica prepared by $\mathrm{NaH}_{2} \mathrm{PO}_{4} 3 \mathrm{~N}$ solution.
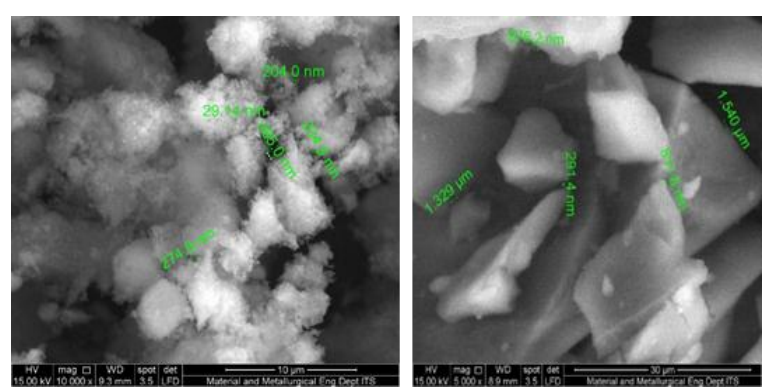

Fig. 5. Microscopy of precipitated silica prepared by a) $\mathrm{Al}_{2}\left(\mathrm{SO}_{4}\right)_{3}$ and b) $\mathrm{NaH}_{2} \mathrm{PO}_{4}$ using sodium silicate solution concentration of $1.6 \%$ (Mag. 10000x) 

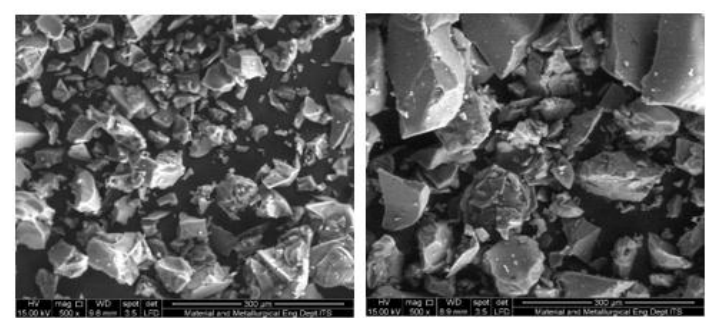

Fig. 6. Morphology of precipitated silica prepared by $\mathrm{NaHPO}_{4}$ using sodium silicate concentration of a) $1.6 \%$ and b) $2.6 \%$ (Mag. 500x)
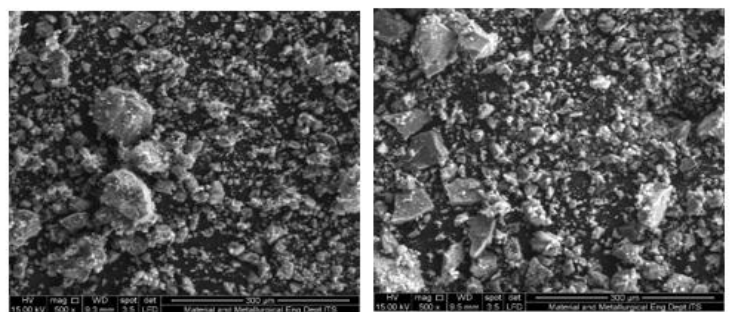

Fig. 7. Morphology of precipitated silica prepared by $\mathrm{Al}_{2}\left(\mathrm{SO}_{4}\right)_{3}$ using sodium silicate concentration of a) $1.6 \%$ and b) $2.6 \%$ (Mag. 500x)

Fig.7 showed the morphology of the precipitated silica product prepared by $\mathrm{NaH}_{2} \mathrm{PO}_{4}$ at magnification of 500 . Figures (a) and (b) show the morphology of silica precipitate using a solution of $\mathrm{Al}_{2}\left(\mathrm{SO}_{4}\right)_{3}$ with a sodium silicate concentration of $1.6 \%$ and $2.6 \%$. Fig.7 (c) and (d) show the morphology of silica precipitate using $\mathrm{Al}_{2}\left(\mathrm{SO}_{4}\right)_{3}$ solution with a sodium silica dilution ratio of $1.6 \%$ and $2.6 \%$. The four images show that the greater the dilution ratio of the sodium silica solution is the denser the particle distance for the two acid salts.

\section{Distribution of particle size of precipitated silica}

Fig.8. showed the particle size distribution of the silica precipitated silica prepared by $\mathrm{Al}_{2}\left(\mathrm{SO}_{4}\right)_{3} 3 \mathrm{~N}$ solution with sodium silicate concentration of $2.6 \%$ (Fig $8 \mathrm{a}$ ) and $1.6 \%$ (Fig.8b). The determined particle size was with calculation of particle diameter method. obtained the particle size about 0.5 $\mu \mathrm{m}$

Fig. 8c showed the particle size of the precipitated silica prepared by $\mathrm{NaH}_{2} \mathrm{PO}_{4} 3 \mathrm{~N}$ with a concentration of sodium silicate $2.6 \%$ having a size in the range of $1-2 \mu \mathrm{m}$. Fig. $8 \mathrm{~d}$ showed the particle size of the precipitated silica prepared by $\mathrm{NaH}_{2} \mathrm{PO}_{4} 3 \mathrm{~N}$ solution with a sodium silicate $1.6 \%$ having a particle size in the range of $1-1.8 \mu \mathrm{m}$.
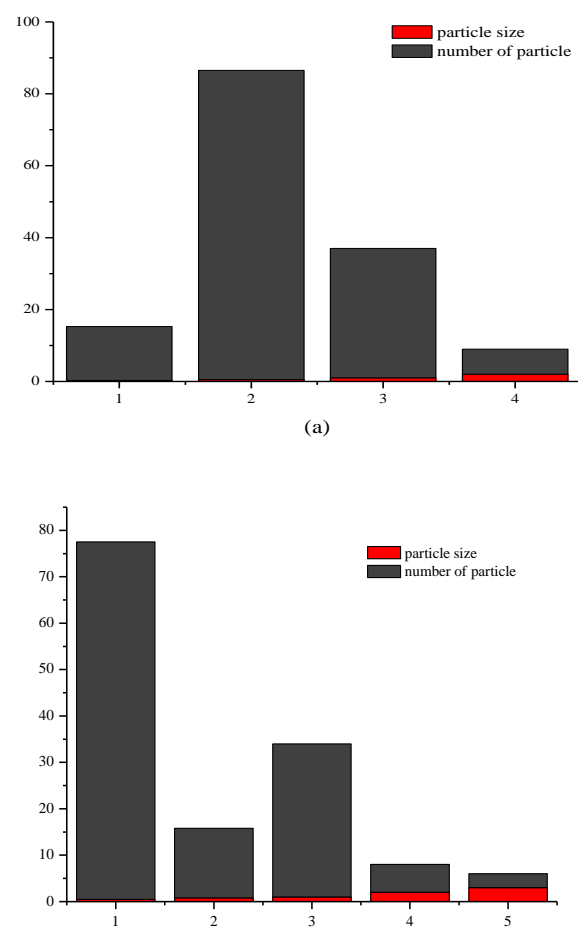

(b)

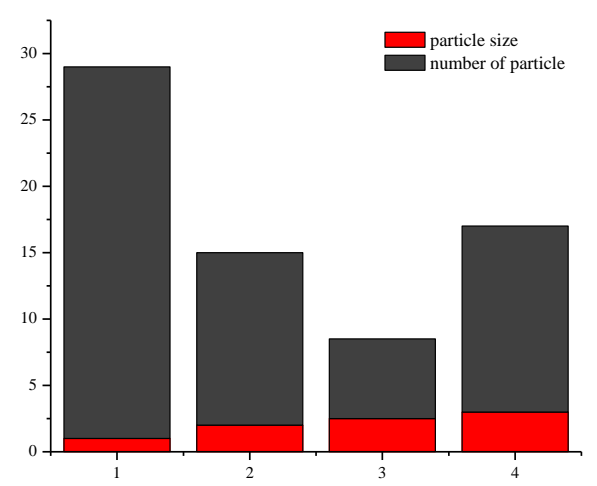

(c)

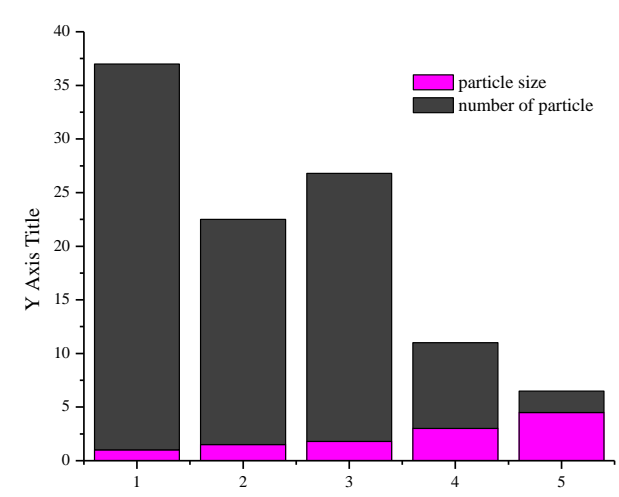

(d)

Fig. 8. Distribution of particle size of precipitated silica 


\section{CONCLUSION}

Precipitated silica concentration of $99 \% \mathrm{SiO} 2$ can be produced from sodium silicate solution using acidic salts $\mathrm{NaH}_{2} \mathrm{PO}_{4}$ solutions, have an amorphous structure and 1-2 $\mu \mathrm{m}$ particle size. Precipitated silica-alumina composite formed by reaction of sodium silicate with $\mathrm{Al}_{2}\left(\mathrm{SO}_{4}\right)_{3}$ salt solution, amorphous structure and about $0.5 \mu \mathrm{m}$ in particle size. The silica content in silica precipitated products prepared by $\mathrm{NaH}_{2} \mathrm{PO}_{4}$ is higher than precipitated silica particle prepared by $\mathrm{Al}_{2}\left(\mathrm{SO}_{4}\right)_{3}$ acid salt solution.

\section{ACKNOWLEDGMENT}

The authors are grateful to group research advanced materials. We also thank PT Geodipa Energi for providing the geothermal sludge. Thanks to Daud Perwira Yudha and Rosyida Nandita for the assistance on this research.

\section{REFERENCES}

[1] S. Music, N. F. Vincekovic, and L. Sekovanic, Precipitation of amorphous $\mathrm{SiO} 2$ particles and their properties, Braz.J. Chem.Eng., 28(1),, pp.89-94, 2011

[2] R.E. Patterson, The Coloid chemistry of silica, The PQ. Corp. R\&D Center, Conchohocken, 2009, pp.618-626.

[3] S. Muljani, H. Setyawan, G. Wibawa, A. Altway, "A Facile method for the production of high-surface-area mesoporous silica gel from geothermal sludge, 25, pp. 1593-1599, 2014

[4] E.A. Gorrepati, P. Wongthahan, S. Raha, H. S. Fogler, Silica precipitation in acidic solutions: Mechanism, $\mathrm{pH}$ effect, and salt effect, Langmuir, 26, pp 10467-10474, 2010

[5] X. Chen, M. Xie, H. Wang, Y. Xue, and Z. Li, Preparation of silica by alkaline-heating and precipitation method from crown ash, BioRes., 9,4, 2014.

[6] Y. Xu, W. Zhang, X. Yue, and D. Zhang, Silica removal using Aluminium Sulphate and sodium aluminate during the bamboo cooking process, Bioresources, 10(4), pp. 7704-7714, 2015 